\title{
Does routine follow up after head injury help? A randomised controlled trial
}

\author{
D T Wade, S Crawford, F J Wenden, N S King, N E G Moss
}

\begin{abstract}
Objective-To evaluate the Medical Disability Society's 1988 recommendation that "every patient attending hospital after a head injury should be registered and offered an outpatient follow up appointment" by determining whether offering a routine follow up service to patients presenting to hospital with a head injury of any severity affects out-
\end{abstract} come six months later.

Design-A randomised controlled trial design with masked assessment of outcome.

Setting-A mixed rural and urban health district with a population of about 560000.

Patients-1156 consecutive patients resident in Oxfordshire aged between 16 and 65 years presenting over 13 months to accident and emergency departments or admitted to hospital and diagnosed as having a head injury of any severity, including those with other injuries.

Interventions-Patients were registered and randomised to one of two groups. Both groups continued to receive the standard service offered by the hospitals. The early follow up group were approached at 7-10 days after injury and offered additional information, advice, support, and further intervention as needed. All randomised patients were approached for follow up assessment six months after injury by independent clinicians blind to their group.

Main outcome measures-Validated questionnaires were used to elicit ratings of post-concussion symptoms (the Rivermead postconcussion symptoms questionnaire), and changes in work, relationships, leisure, social, and domestic activities (the Rivermead head injury follow up questionnaire).

Oxford Head Injury Service, Rivermead Rehabilitation Centre, Abingdon Road, Oxford OX1 4XD, UK D T Wade $S$ Crawford F J Wenden NS King

N E G Moss

Correspondence to Dr D T Wade.

Received 14 May 1996 Accepted for publication 11 December 1996 fewer difficulties with everyday activities $(\mathbf{P}=0.03)$.

Conclusions-The results from the $41 \%$ of patients followed up do not support the recommendation of offering a routine follow up to all patients with head injury, but they do suggest that routine follow up is most likely to be beneficial to patients with moderate or severe head injuries. Some of those with less severe injuries do continue to experience difficulties and need access to services. A further trial is under way to test these conclusions.

(F Neurol Neurosurg Psychiatry 1997;62:478-484)

Keywords: randomised controlled trial; head injury; follow up service

Head injuries are extremely common, and improved management could potentially lead to great benefit. Epidemiological studies suggest that there are 250-300 hospital admissions in Britain involving head injury per 100000 of the population. ${ }^{1}$ With conventional measures to estimate severity, it is probable that a minimum of $75 \%$ of these injuries are mild or moderate ${ }^{2}$ and as few as $7 \%$ are severe. ${ }^{3}$ Services for people with head injury have normally focused on the more severely impaired patients.

However, less severely injured patients may also experience a range of postconcussion symptoms. These usually resolve between three and six months after injury ${ }^{4-7}$ although some patients have symptoms which persist up to or beyond one year. ${ }^{89}$ These symptoms after mild head injury may be due to diffuse axonal injury ${ }^{10}$ and slowing of information processing, which usually recovers over four to eight weeks, ${ }^{11}$ but is worse after recurrent injury. ${ }^{12}$ Thus although many people will have no adverse effects after mild head injury, up to half may develop postconcussion symptoms, which may include headaches, dizziness, fatigue, irritability, reduced concentration, sleep disturbance, memory dysfunction, anxiety, sensitivity to noise or light, double or blurred vision, and depression. ${ }^{1314}$ These symptoms may cause significant psychosocial problems for the patient, both at home and at work, ${ }^{1516}$ and often coincide with neuropsychological impairments. ${ }^{11} 17$

The management of problems arising after head injury of any severity is poorly 
researched. One controlled unmatched nonrandomised study investigated case management for patients with severe injuries, ${ }^{18}$ and found that early case management of severe head injury did not affect outcome. Controlled treatment trials for less severe head injuries have used psychological interventions including reassurance and information giving, ${ }^{19} 20$ and found significant reductions in the intensity of some symptoms or significantly quicker return to work in those patients in the treatment groups.

In 1988 the Medical Disability Society recommended, without supporting evidence, that "every patient attending hospital after a head injury should be registered and offered an outpatient follow up appointment". ${ }^{21}$ This study tests this recommendation, investigating whether offering a routine early follow up service to patients presenting to hospital with a head injury, of any severity, affected their outcome six months later.

\section{Methods}

The study aimed to include all patients aged 16-65 years resident in Oxfordshire (total population 560 000; health authority Code K41) who presented to hospital services with a head injury of any severity and regardless of any additional injuries. The definition of head injury used was: "any blow to the head causing a clinical diagnosis of head injury to be made, even if insufficient to cause definite loss of consciousness". Ethical approval for the study was obtained. Patients were notified to the head injury register set up by the Oxford Head Injury Service (OXHIS) from either the accident and emergency departments or the admitting wards under the trauma service. ${ }^{22}$

Between February 1993 and March 1994, 1186 patients were registered, of whom 1156 were randomised into two equal groups, using a list of computer generated random numbers: 30 patients notified to the register more than three months after injury were not randomised. Both groups continued to have access to existing hospital services such as the outpatient fracture clinic, but normal clinical services locally do not include routine follow up of patients attending or admitted to hospital after an uncomplicated head injury. The early follow up group, which will be referred to as the "trial" group, received the additional service from OXHIS. Those receiving only the usual hospital services and not contacted until six months after injury will be referred to as the control group. All those randomised were sent a letter explaining the purpose of the study, the prospect of follow up at six months after injury, and the possibility of early follow up. Most patients, $(78 \%)$, had not been admitted to hospital and, of those who had, most had left hospital by the time of randomisation and notification. Routine assessment of all patients at the time of randomisation was not possible for various reasons: the simple fact of assessment by an interested person might have been therapeutic; notification usually occurred after the patient had left hospital; and the resources available to the study were limited.

\section{THE INTERVENTION}

Patients randomised to the trial group to receive the additional service were approached at seven to 10 days after injury, or as soon as possible after notification. When telephone numbers were not available, the approach was by letter. The clinicians, an occupational therapist, and a clinical psychologist tried to see patients face to face wherever and whenever was most convenient for the patients. If it was impossible either to contact the patient by telephone, or to see them in person, they were sent a letter inviting them to contact the service if advice and support were needed.

All patients in the trial group were sent or given an information sheet on the management of possible symptoms after head injury. ${ }^{23}$ All those interviewed either face to face or by telephone were given a brief standard assessment including the collection of basic epidemiological data, the administration of the Rivermead postconcussion symptom questionnaire (RPQ), ${ }^{2324}$ and the estimation of the length of post-traumatic amnesia (PTA). ${ }^{2526}$ All further interventions were in response to identified clinical need and included counselling, neuropsychological assessment, and treatment, cognitive behavioural psychotherapy, or referral on to other specialist services. The amount and types of services are described in detail in another paper, ${ }^{27}$ but considering all patients randomised to the trial group (not all of whom were seen at six months): 240 patients received postal information only and were not otherwise in contact with the service; 127 had telephone contact, advice, and information; 93 were seen in person, assessed, and given advice and information; 78 needed more help and support from the OXHIS team over the telephone; and 33 required further face to face contact either from OXHIS or other services. All patients were advised that they could have continued access to the service at any time, either by telephone or face to face, to discuss any concerns, and would be offered additional assessment and treatment if required.

\section{FOLLOW UP}

At six months after injury, all randomised patients were approached by one of two clinicians who had not been involved in the early follow up service, and who remained unaware to which group patients had been assigned. Fifty seven patients had moved away from the area, were itinerant, had died, or had requested no further contact. The remaining 1099 patients were approached by letter asking whether they were willing to be followed up. For those with a telephone, $(n=785)$, the letter was followed by a call to arrange for a clinician to see them, or to interview them over the telephone. Those for whom no telephone number was available $(n=314)$ received a reply slip attached to their letter, to be returned in an enclosed stamped, addressed envelope if they were willing to be interviewed. 
Table 1 Data on age, sex, and hospital admission for those interviewed or not interviewed (including those not contacted) at follow up

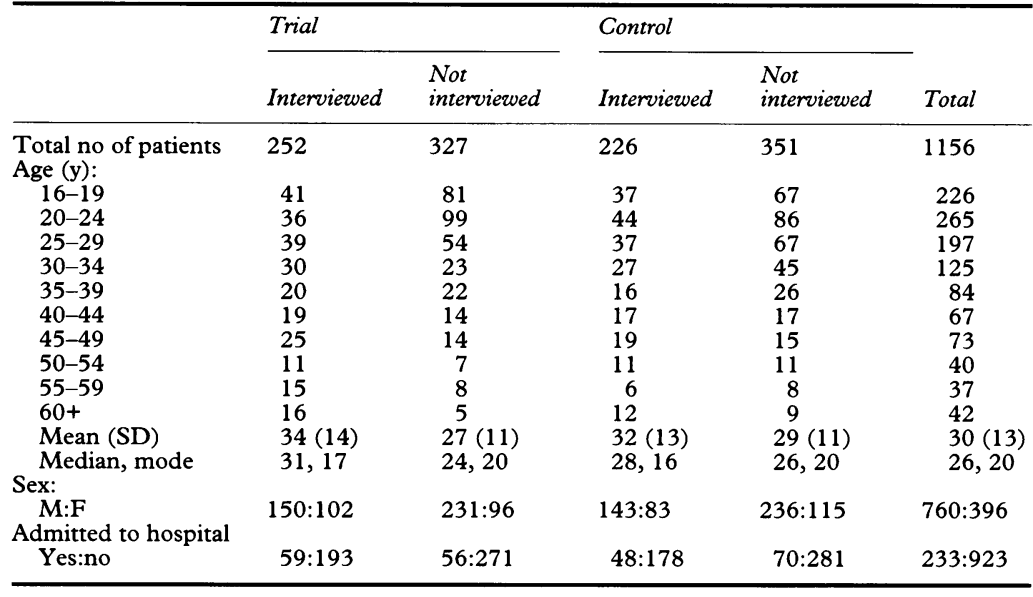

Major efforts were made to achieve follow up, including telephoning in the evenings and making several attempts to contact patients. At the six month interview, the clinicians also offered information, advice, and support if appropriate and arranged further services if necessary.

Assessment at six month follow up included the collection of basic demographic data, an assessment of postconcussion symptoms using the RPQ and the completion of a subjective rating scale of outcome, the Rivermead head injury follow up questionnaire (RHFUQ) ${ }^{28}$ covering changes in work, relations, leisure, social, and domestic activities. Duration of PTA was estimated to give an indication of the severity of injury using published criteria, and the data on PTA collected at six months were used in all statistical analyses; ${ }^{25} 26$ this has been shown to be reliable. ${ }^{26}$ Power calcula-

Table 2 Demographic data from patients interviewed at six months

\begin{tabular}{|c|c|c|c|}
\hline & $\begin{array}{l}\text { Trial } \\
(n(\%))\end{array}$ & $\begin{array}{l}\text { Control } \\
(n(\%))\end{array}$ & Total \\
\hline $\begin{array}{l}\text { Total no of patients } \\
\text { Marital status: }\end{array}$ & $252(100)$ & $226(100)$ & 478 \\
\hline Single adult $(18+y)$ & $91(36)$ & $73(32)$ & 164 \\
\hline Married/cohabiting & $124(49)$ & $115(51)$ & 239 \\
\hline Child $<18$ & $15(6)$ & $21(9)$ & 36 \\
\hline Divorced/widowed/separated & $22(9)$ & $17(8)$ & 39 \\
\hline \multicolumn{4}{|l|}{ Employment: } \\
\hline Child & $12(5)$ & $19(8)$ & 31 \\
\hline Full time employment & $140(55)$ & $126(56)$ & 266 \\
\hline Part time employment & $23(9)$ & $16(7)$ & 39 \\
\hline Full time housework & $3(1)$ & 1 & 4 \\
\hline Unemployed: seeking work & $15(6)$ & $11(5)$ & 26 \\
\hline Unemployed: not seeking work & $21(8)$ & $18(8)$ & 39 \\
\hline Student & $17(7)$ & $18(8)$ & 35 \\
\hline Retired/other & $21(8)$ & $17(8)$ & 38 \\
\hline \multicolumn{4}{|l|}{ Accident type: } \\
\hline \multicolumn{4}{|l|}{ Road traffic accident } \\
\hline including pedestrian & $59(23)$ & $64(28)$ & 123 \\
\hline Horse riding & $12(5)$ & $9(4)$ & 21 \\
\hline Domestic accident & $42(17)$ & $30(13)$ & 72 \\
\hline Work accident & 45 (18) & $30(13)$ & 75 \\
\hline Assault & 28 (11) & $33(15)$ & 61 \\
\hline Other & $66(26)$ & $61(27)$ & 126 \\
\hline \multicolumn{4}{|l|}{ Associated injuries: } \\
\hline None & $56(22)$ & $57(25)$ & 113 \\
\hline Minor only & $154(61)$ & $133(59)$ & 287 \\
\hline One fracture & $21(8)$ & $23(10)$ & 44 \\
\hline Two or more fractures & $16(7)$ & $8(4)$ & 24 \\
\hline Very severe & $5(2)$ & $4(2)$ & 9 \\
\hline Not known & - & 1 & 2 \\
\hline \multicolumn{4}{|c|}{ Post-traumatic amnesia as estimated at six month follow up: } \\
\hline Under 1 hour & $161(64)$ & $154(68)$ & 315 \\
\hline $1-24$ hours & $54(21)$ & $42(19)$ & 96 \\
\hline 1-7 days & $11(4)$ & $7(3)$ & 18 \\
\hline Over 7 days & $6(2)$ & $4(2)$ & 10 \\
\hline Not known & $20(8)$ & $19(8)$ & 39 \\
\hline
\end{tabular}

tions could not be made in the absence of any relevant data concerning the outcomes to be expected in this group of patients. Statistical tests used to compare groups were primarily for non-parametric data and included the $\chi^{2}$ test and the Mann-Whitney $U$ test, with two tailed $p$ values being used.

\section{Results}

A total of 1156 patients were randomised, 579 to the trial group and 577 to the control group. The only data available on all patients registered (including those not to be contacted at six months) related to age and sex. (Accident and emergency notes rarely record consistent or reliable data, and our resources did not allow us to trace over 1000 sets of notes, many of which would not have been traceable.) At follow up six months after injury, interviews were conducted with 478 patients (252 trial group, 226 control group). The control and trial groups were comparable in terms of age and sex at randomisation. The groups remained comparable at follow up interview, but the patients not followed up were younger and more likely to be male, with a pronounced loss among those aged under 25 years, in both groups (table 1). There was no evidence of selective follow up in the trial group.

$\chi^{2}$ testing of additional data collected at six months follow up showed no significant differences between patients in the trial and control groups in terms of marital status, employment situation, cause of injury, associated injuries sustained, hospital admission, or severity of head injury (PTA) (table 2).

The frequency and subjective severity with which post concussion symptoms were experienced was assessed using the RPQ. Ratings were totalled to give an overall indication of the level of symptoms, ${ }^{23}{ }^{24}$ and there was no significant difference between the groups (Mann-Whitney $U$ test: $z=-0.76 ; \mathrm{P}=0.44$ ). Many patients in both groups (average $45 \%$ ) rated all symptoms as either not a problem or no more of a problem than before their head injury (table 3 ).

The extent to which patients were experiencing changes to their everyday activities and relations at six month follow up were assessed using the RHFUQ. Ratings were totalled to give an overall indication of the level of change, ${ }^{28}$ and there was no significant difference between the groups (Mann-Whitney $U$ test: $z=-0.75 ; P=0.45)$. Many patients in both groups (mean 57\%) reported no changes in their everyday activities compared with before their head injury, (table 4).

It was clear that many patients assessed at six months had sustained only very mild head injuries and were unlikely to have needed any intervention: 212 patients reported no PTA and 103 reported PTA of under one hour. A subgroup analyses was undertaken, restricting comparison between the trial and control groups to patients with more severe head injuries as judged by duration of PTA as estimated at six month follow up: patients with a PTA of one hour or more were considered to 
Table 3 Patients reporting postconcussion symptoms at six month follow up

\begin{tabular}{lccr}
\hline & $\begin{array}{l}\text { Trial } \\
(n(\%))\end{array}$ & $\begin{array}{l}\text { Control } \\
(n(\%))\end{array}$ & Total \\
\hline Total no of patients & $252(100)$ & $226(100)$ & 478 \\
Symptoms: & $59(23)$ & $58(26)$ & 117 \\
Headache & $20(8)$ & $18(8)$ & 38 \\
Nausea/vomiting & $48(19)$ & $30(13)$ & 78 \\
Dizziness & $44(18)$ & $30(13)$ & 74 \\
Noise sensitivity & $51(20)$ & $45(20)$ & 96 \\
Sleep disturbance & $76(30)$ & $67(30)$ & 143 \\
Fatigue & $56(22)$ & $55(24)$ & 111 \\
Irritability & $56(22)$ & $44(20)$ & 100 \\
Feeling depressed & $57(23)$ & $38(17)$ & 95 \\
Feeling frustrated & $80(32)$ & $44(20)$ & 124 \\
Poor memory & $57(23)$ & $36(16)$ & 93 \\
Poor concentration & $62(25)$ & $44(20)$ & 106 \\
Taking longer to think & $20(8)$ & $24(11)$ & 44 \\
Blurred vision & $23(9)$ & $20(9)$ & 43 \\
Sensitivity to light & $1(1)$ & $2(1)$ & 3 \\
Double vision & $37(15)$ & $40(18)$ & 77 \\
Restlessness & $106(42)$ & $101(45)$ & 207 \\
RPQ sum total ratings: & $99(39)$ & $91(40)$ & 190 \\
0 & $36(14)$ & $24(11)$ & 60 \\
2-16 & $10(4)$ & $10(4)$ & 20 \\
17-32 & 1 & 0 & 1 \\
33-48 & $7 \cdot 7(10 \cdot 9)$ & $6 \cdot 8(10 \cdot 0)$ & \\
49-64 & 2 & 2 & \\
Mean (SD) & & & \\
Median & & &
\end{tabular}

$\mathrm{RPQ}=$ Rivermead postconcussion symptoms questionnaire.

Table 4 Frequency of reported changes in work, relationships, social and leisure activities at six months

\begin{tabular}{lccr}
\hline & $\begin{array}{l}\text { Trial } \\
(n(\%))\end{array}$ & $\begin{array}{l}\text { Control } \\
(n(\%))\end{array}$ & Total \\
\hline Total no of patients & $252(100)$ & $226(100)$ & 478 \\
Item: & $29(11)$ & $15(7)$ & 44 \\
Participating in conversation with one person & $42(17)$ & $24(11)$ & 66 \\
Participating in conversation with 2+ people & $25(10)$ & $19(8)$ & 44 \\
Performing routine domestic activities & $37(15)$ & $31(14)$ & 68 \\
Participating in previous social activities & $42(17)$ & $33(15)$ & 75 \\
Participating in previous leisure activities & $32(13)$ & $31(14)$ & 63 \\
Maintaining previous work load & $56(22)$ & $55(24)$ & 111 \\
Finding work more tiring & $21(8)$ & $24(11)$ & 45 \\
Relationships with friends & $17(7)$ & $15(7)$ & 32 \\
Relationship with partner & $31(12)$ & $21(9)$ & 52 \\
Ability to cope with family damands & $142(56)$ & $132(58)$ & 274 \\
RHFUQ sum total ratings: & $76(30)$ & $72(32)$ & 148 \\
0 & $28(11)$ & $14(6)$ & 42 \\
1-10 & $5(2)$ & $5(2)$ & 10 \\
11-20 & $1(1)$ & $3(1 \cdot 5)$ & 4 \\
$21-30$ & $3.6(6.0)$ & $3.3(6.3)$ & \\
31-40 & & & \\
Mean (SD) & &
\end{tabular}

RHFUQ = Rivermead head injury follow up questionnaire.

have had a more significant head injury. ${ }^{25}$ The subgroup analysis was restricted to the sum total ratings for the RPQ and RHFUQ and was only considered after the main analysis was complete.
The data in table 5 confirm that patients with more significant head injuries as judged by PTA were more likely to have postconcussion symptoms at six months. Furthermore, the data show that there were no significant differences between trial and control patients with more significant head injuries in terms of the extent of residual PCS symptoms at six months on the RPQ (Mann-Whitney $U$ test: $z$ $=1.42 ; P=0.16)$. Patients in the control group with a PTA $\geqslant$ one hour were more likely to have continuing difficulties at six months, as identified by the RHFUQ, than those in the trial group, (Mann-Whitney $U$ test: $z=-2 \cdot 13 ; \mathrm{P}=0.03$ ). The same analysis was conducted with patients selected by virtue of PTA of one hour or more and hospital admission, and showed similar results (table 5, Mann-Whitney $U$ test: $z=-2.07 ; \mathrm{P}=0.04)$. By contrast there were no significant differences between patients in the two groups with PTA $>0 \leqslant 0.05$ hours (Mann-Whitney $U$ test: $z=-0.79, \mathrm{P}=0.43)$, with PTA $>0.05$ $<$ one hour and with PTA $=0$ (MannWhitney $U$ test: $z=-0.40, P=0.69)$. Thus there was no evidence to suggest that patients with less severe head injury were harmed by the intervention.

The intervention provided at initial follow up varied. Of those patients interviewed at six months, no contact had been attempted with one, for whom no address was available. The remaining 251 were all sent or given written information and advice about coping with head injury. After this, $67(27 \%)$ did not respond to the invitation to contact the service, $68(27 \%)$ were contacted and given advice over the telephone, $54(21 \%)$ were interviewed face to face, $44(18 \%)$ required additional telephone support, and $18(7 \%)$ required further face to face contact. Initial follow up was also provided for 327 patients who were not seen at six months. No contact was attempted for seven (2\%) patients for various practical reasons. The remaining 320 were all sent or given written information: 173 (53\%) did not respond to the invitation to contact the service, $59(18 \%)$ were contacted

Table 5 Subgroup analysis of RPQ and RHFUQ ratings at 6 months follow up

\begin{tabular}{|c|c|c|c|c|c|c|c|c|}
\hline & \multicolumn{2}{|l|}{ Trial } & \multicolumn{2}{|l|}{ Control } & \multicolumn{2}{|l|}{ Trial } & \multicolumn{2}{|l|}{ Control } \\
\hline & $\begin{array}{l}\text { PTA } \\
<1 \\
\text { hour } \\
(n(\%))\end{array}$ & $\begin{array}{l}P T A \\
\geqslant 1 \\
\text { hour } \\
(n(\%))\end{array}$ & $\begin{array}{l}P T A \\
<1 \\
\text { hour } \\
(n(\%))\end{array}$ & $\begin{array}{l}P T A \\
\geqslant 1 \\
\text { hour } \\
(n(\%))\end{array}$ & $\begin{array}{l}\text { Admitted } \\
\text { and } \\
P T A<1 \\
\text { hour } \\
(n(\%))\end{array}$ & $\begin{array}{l}\text { Admitted } \\
\text { and } \\
P T A \geqslant 1 \\
\text { hour } \\
(n(\%))\end{array}$ & $\begin{array}{l}\text { Admitted } \\
\text { and } \\
P T A<1 \\
\text { hour } \\
(n(\%))\end{array}$ & $\begin{array}{l}\text { Admitted } \\
\text { and } \\
P T A \geqslant 1 \\
\text { hour } \\
(n(\%))\end{array}$ \\
\hline $\begin{array}{l}\text { Total no of patients } \\
\text { RPQ sum total ratings: }\end{array}$ & 161 & 71 & 154 & 53 & 14 & 31 & 10 & 30 \\
\hline $\begin{array}{l}0 \\
2-16 \\
17-32 \\
33-48 \\
49-64 \\
\text { Median } \\
\text { Mean (SD) } \\
\text { RHFUO sum total ratings: }\end{array}$ & $\begin{array}{l}85(53) \\
55(34) \\
18(11) \\
3(2) \\
0 \\
1 \\
1 \cdot 62(0 \cdot 76)\end{array}$ & $\begin{array}{l}19(27) \\
36(51) \\
11(15) \\
5(7) \\
0 \\
2 \\
2 \cdot 03(0 \cdot 85)\end{array}$ & $\begin{array}{l}86(56) \\
57(37) \\
9(6) \\
2(1) \\
0 \\
1 \\
1.53(0.67)\end{array}$ & $\begin{array}{l}11(21) \\
25(47) \\
12(23) \\
5(9) \\
0 \\
2 \\
2 \cdot 21(0 \cdot 89)\end{array}$ & $\begin{array}{l}6(43) \\
5(36) \\
3(21) \\
= \\
2 \\
1 \cdot 79(0 \cdot 80)\end{array}$ & $\begin{array}{l}8(26) \\
18(58) \\
4(13) \\
1(3) \\
-2 \\
1.94(0 \cdot 73)\end{array}$ & $\begin{array}{l}2(20) \\
6(60) \\
2(20) \\
-\quad \\
2 \\
2 \cdot 0(0 \cdot 67)\end{array}$ & $\begin{array}{l}6(20) \\
15(50) \\
7(23) \\
2(7) \\
\frac{2}{2} \\
2 \cdot 17(0 \cdot 83)\end{array}$ \\
\hline $\begin{array}{l}\text { RHFUQ sum total ratings: } \\
0 \\
1-10 \\
11-20 \\
21-30 \\
31-40 \\
\text { Median } \\
\text { Mean (SD) } \\
\text { Missing } \\
\end{array}$ & $\begin{array}{l}110(68) \\
38(24) \\
9(6) \\
3(2) \\
0 \\
0 \\
0 \cdot 41(0 \cdot 69) \\
1\end{array}$ & $\begin{array}{l}29(41) \\
28(39) \\
11(15) \\
2(3) \\
1(2) \\
1 \\
0.85(0 \cdot 89)^{\star} \\
0\end{array}$ & $\begin{array}{l}110(71) \\
38(25) \\
4(3) \\
2(1) \\
0 \\
0 \\
0 \cdot 34(0 \cdot 60) \\
0\end{array}$ & $\begin{array}{l}14(26) \\
25(47) \\
8(15) \\
3(6) \\
3(6) \\
1 \cdot 17(1 \cdot 07)^{\star} \\
1 \cdot 17 \\
0\end{array}$ & $\begin{array}{l}8(57) \\
5(36) \\
1(7) \\
= \\
0 \\
0 \cdot 50(0 \cdot 65)\end{array}$ & $\begin{array}{l}14(45) \\
12(39) \\
4(13) \\
1(3) \\
-1 \\
0.74(0.82) \dagger\end{array}$ & $\begin{array}{l}2(20) \\
7(70) \\
1(10) \\
= \\
1 \\
0.90(0.57)\end{array}$ & $\begin{aligned} 7(23) \\
15(50) \\
5(17) \\
1(3) \\
2(7) \\
1.20(1 \cdot 06) \dagger \\
1 \cdot 20\end{aligned}$ \\
\hline
\end{tabular}


and given advice over the telephone, $39(12 \%)$ were interviewed face to face, $34(10 \%)$ required additional telephone support, and 15 $(5 \%)$ required further face to face contact.

The impartiality of the clinicians conducting the six month follow up was tested by asking them to guess whether patients being interviewed belonged to the trial or control group. The clinicians were only $60 \%$ successful, suggesting that they were effectively blinded to the conditions.

\section{Discussion}

The results of this large scale randomised controlled trial of head injury rehabilitation does not provide evidence to support the Medical Disability Society's 1988 recommendation for the routine follow up of all patients with head injury aged 16-65. Using the outcome measures described at six months after injury, ${ }^{24} 28$ no significant benefit to the group offered follow up was shown. However, subgroup analysis indicated that patients with moderate or severe head injuries (PTA of one hour or more) do benefit from routine follow up soon after injury. Patients with less severe head injury showed no difference in outcome. This study was run as part of an innovative clinical service including as many patients (age range 16-65) as possible, and is therefore subject to some methodological and analytical problems.

The problems of defining and registering patients with head injury have already been discussed in relation to this study. ${ }^{22}$ Not all patients will have been notified to the service, and other clinicians might not agree on the diagnosis of head injury in every case. However, the number of patients in the age range studied was that anticipated. We think that the patients randomised were adequately representative of patients receiving existing clinical services for head injury.

There was minimal baseline information on patients because there was no routine assessment at the time of notification and randomisation. The very process of contacting all patients randomised in order to collect clinical data related to their injury would probably have been therapeutic, as giving information and reassurance could not be avoided. The study would then have been distorted. Considerable resources would have been required to contact and interview every patient, because most are treated in casualty and sent home immediately. Routine data are poor: PTA is often not assessed in the casualty department in patients with minor head injuries and was not available for a small group of patients when assessed at six months; PTA collected at six months is valid and reliable. ${ }^{26}$ It was accepted, therefore, that only basic data on all patients could be collected, and it was anticipated that randomisation would ensure that the two groups were comparable. Minor differences, such as more patients having memory problems in one group (table 3) probably arise through chance.

More than half of all patients randomised were lost to six month follow up. This reflects clinical realities. Many patients have trivial injuries and understandably see no point in being involved with medical services. Many are young, moving from place to place, and not easily traced. It is possible that a few might have chosen not to be interviewed because of problems arising from the head injury, (for instance, lack of motivation or insight, or posttraumatic stress). It is also worth noting that many patients in the trial group who had received the service none the less chose not to be followed up at six months. Every effort was made to maximise follow up, including repeated telephone calls. Unlike in other studies, follow up was under $50 \%$ because the study population comprised young, working people, or students, or people involved in violence, and they often changed address. Because the patients often did not have any appreciable problems, they were unlikely to be motivated to participate even in a telephone interview. Within the limitations of the data, there was no evidence of selective follow up and we think that the data are unbiased and the results are valid.

It is also possible that the clinicians were biased in favour of one or other group, despite not having been involved in early follow up. It is obviously impossible to prevent all patients from giving information which might identify their group at interview. Nevertheless, the clinicians guessed the patient's group correctly in only $60 \%$ of cases. Significant observer bias seems unlikely.

The main study found no differences between the two groups. This might be because the measures were insufficiently sensitive; the measures failed to assess the relevant problems and difficulties; patient numbers were too small to detect a real difference; the intervention was too limited to lead to any difference; intervention only reached a proportion of possible patients; early differences between the groups were obscured by six months; or no intervention was needed for many patients.

The study required measures to be used with a wide range of patients, including the majority with mild injuries. Most existing measures have been designed for use with patients with severe head injuries, and require long interviews and formal testing. Measures were needed which would not be too time consuming (follow up interviews averaged 30 minutes), and which could be undertaken by telephone interview if necessary. The two measures used were designed and subjected to formal evaluation at an earlier stage of the study, and there is evidence to support their reliability and validity. ${ }^{232428}$ The measures might have missed significant problem areas or might have been insufficiently sensitive to detect some changes. Without information on the outcomes to be expected using the measures, it was not possible to calculate the power of the study.

Information about the emotional state of patients and carers was measured using the general health questionnaire, 28 question version, ${ }^{29}$ but insufficient questionnaires (patients 
$\mathrm{n}=260$, carers $\mathrm{n}=117$ ) were completed to draw any conclusions.

Only a minority of patients in the trial group who were followed up at six months $(25 \%)$ had more than a single intervention at early follow up. Both treating clinicians had considerable knowledge and experience of management of head injury, and had access to further expert advice if needed. It seems probable that the patients received appropriate interventions and could be given whatever they needed, and it is unlikely that any existing service could offer a better follow up.

The most likely explanation for the lack of any measured difference between the groups is that routine follow up of all patients does not benefit a sufficient number to be detected in the results of the whole group. It is quite possible that some patients with less significant head injuries might benefit from follow up; the problem is to identify them. ${ }^{22}$ Even in the group followed up, which was likely to be biased towards patients with continuing problems, there were many patients without persisting problems. Although a substantial proportion continued to experience difficulties to varying degrees, many made a full recovery, recording no persisting symptoms or problems at six months, and any benefit to a subgroup of patients may have been hidden by the large number of patients without difficulties.

This explanation justified our subgroup analysis. It seemed probable that patients with more severe head injuries were more likely to face problems and more likely to benefit from intervention. Severity of head injury was determined primarily using PTA, the most widely used measure of severity. A cut off of one hour was selected as indicating a significant head injury. ${ }^{25}$ Admission to hospital was also chosen both as a surrogate indication of severity and because it was easier to generalise to other settings. We did not use the Glasgow coma scale because this information was not available for most patients with mild injuries who would in any case have achieved maximum scores.

The subgroup analysis suggests that patients with moderate or severe injuries do benefit from early follow up. It is of particular interest that there were no differences between trial and control groups in terms of the RPQ sum total ratings, implying similar levels of postconcussion symptoms at six months. Despite this there were significant differences between the trial and control groups' RHFUQ ratings. This suggests that the impact these symptoms make upon the everyday lives of patients (as measured using the RHFUQ) had been lessened in the trial group by the intervention they had received, perhaps by increasing their ability to cope. There was no evidence that those patients in the trial group whose PTA was less than one hour were harmed by focusing attention on possible symptoms.

Any conclusions drawn from subgroup analysis need cautious interpretation, but the underlying hypothesis is clinically sensible, and the difference seen in RHFUQ ratings was consistent and significant. The lack of differ- ence in RPQ sum total ratings does suggest that the selected control and trial groups were still comparable.

In conclusion, the results suggest that follow up services for patients with moderate or severe head injuries are most likely to be of benefit but it should not be assumed that services do not need to be available for less severely injured patients. Of patients whose PTA was one hour or more, $41 \%$ of those in the trial group reported no problems on the RHFUQ compared with $26 \%$ of patients in the control group. A further randomised controlled trial is being undertaken to determine whether these patients do indeed benefit from early follow up and an "opt in" service is being offered to those less severely injured. It is hoped that the results will provide further evidence to enable services to be targeted more effectively.

We acknowledge the help of all the patients who took part: the staff in the trauma services; all clinicians and others in the various hospitals who helped in the running of the register, especially D Powers; the Department of Health who are funding the Cxford Head Injury Service as part of its Traumatic Brain Oxford Head Injury Service as part of its Traumatic Brain
Injury Initiative; and Mrs Ann White for maintaining the Injury Initiative; and Mrs Ann White for maintaining the
Oxford Head Injury Service register and organising randomisaOxfor.

1 Jennett B, MacMillan R. Epidemiology of head injury. BMF 1981;282:101-4.

2 Kraus JF, Nouriah P. The epidemiology of mild uncomplicated brain injury. Trauma 1988;28:1637-43.

3 Artiola I, Fortuny L, Briggs M, Newcombe F, Ratcliff G Thomas C. Measuring the duration of post-traumatic Thomas C. Measuring the duration of post-traumatic

4 Alves WM, Colohan ART, O'Leary TJ, Rimel RW, John JA. Understanding post-traumatic symptoms after minor head injury. Fournal of Head Trauma Rehabilitation 1986; 1:1-12.

5 Leninger BE, Gramling SE, Farrel AD. Neuropsychological deficits in symptomatic minor head injury
patients after concussion and mild concussion. $\mathcal{F}$ Neurol Neurosurg Psychiatry 1990;53:293-6.

6 Evans RW. The postconcussion syndrome and the sequelae of mild head injury. Neurol Clin, 1992;10:815-47.

7 Englander J, Hall K, Simpson T, Chaffin S. Mild traumatic brain injury in an insured population; subjective complaints and return to employment. Brain Inj 1992;6: plaints

8 Rutherford WH, Merrett JD, McDonald JR. Symptoms at one year following concussion from minor head injuries. Injury 1979;10:225-30.

9 Middelboe T, Anderson HS, Birket-Smith M, Friis ML. Minor head injury: impact on general health after one year. A prospective follow up study. Acta Neurol Scand 1992;85:5-9.

10 Oppenheimer DR. Microscopic lesions in the brain following head injury. F Neurol Neurosurg Psychiatry 1968;31: 299-306.

11 Gronwall D, Wrightson P. Delayed recovery in intellectual function after mild head injury. Lancet 1974;ii:605-9.

12 Gronwall D, Wrightson P. Cumulative effects of concussion. Lancet 1975;ii:995-7.

13 Mandel S. Minor head injury may not be "minor". Postgrad Med 1989;85:213-25.

14 Binder LM. Persisting symptoms after mild head injury. A review of the postconcussive syndrome. F Clin Exp review of the postconcussi

15 Dikmen SS, McLean A, Temkin N. Neuropsychological and psychosocial consequences of minor head injury. $\mathcal{F}$ Neurol Neurosurg Psychiatry 1986;49:1227-32.

16 Dikmen SS, Temkin N, Armsden A. Neuropsychological recovery; the relationship to psychosocial functioning and post concussional complaints. In: Levin $\mathrm{H}$, Eisenberg $\mathrm{HM}$, Benton AL, eds. Mild head injury. New York: Oxford University Press, 1989.

17 Bohnen N, Twijnstra A, Jolles J. Post-traumatic and emotional symptoms in different sub groups of patients with mild head injury. Brain Inj 1992;6:481-6.

18 Greenwood RJ, McMillan TM, Brooks DN, et al. Effects of case management after severe head injury. $B M F$ 1992; 308:1199-205.

19 Minderhoud JM, Boelens MEM, Huizenga J, Saan RJ Treatment of minor head injuries. Clin Neurol Neurosurg 1980;82:127-40.

20 Relander $M$, Troupp H, Bjorkesten af G. Controlled trial of treatment for cerebral concussion. BMF 1972;4:777-9.

21 Medical Disability Society. The management of traumatic brain injury. London: The Medical Disability Society, brain 
22 Moss NEG, Powers D, Wade DT. The Oxford head injury register. Disability and Rehabilitation 1996;18:169-73.

23 Moss NEG, Crawford S, Wade DT. Post concussion symptoms-is stress a mediating factor? Clinical symptoms-is stress a m
Rehabilitation 1994;8:149-56.

24 King NS, Crawford S, Wenden FJ, Moss NEG, Wade DT. The Rivermead post concussion symptom questionnaire: a measure of symptoms commonly experienced after head injury and its reliability. $\mathcal{F}$ Neurol 1995;242:587-92.

25 Russell WR, Smith A. Post-traumatic amnesia after closed head injury. Arch Neurol 1961;5:16-29.

26 King NS, Crawford S, Wenden FJ, Moss NEG, Wade DT, Caldwell FE. Measurement of post-traumatic amnesia: how reliable is it? $\mathcal{f}$ Neurol Neurosurg Psychiatry 1997; 62:38-42.

27 King NS, Crawford S, Wenden FJ, Moss NEG, Wade DT Interventions and service need following mild and moderate head injury: The Oxford Head Injury Service. Clinical Rehabilitation 1997;11:13-27.

28 Crawford S, Wenden F, Wade DT. The Rivermead head injury follow up questionnaire: a study of a new rating scale and other measures to evaluate outcomes following head injury. $f$ Neurol Neurosurg Psychiatry 1996;60 510-14.

29 Goldberg DP, Hillier VF. A scaled version of the general health questionnaire. Psychol Med 1979;9:139-45.

\section{HISTORICAL NOTES}

\section{Robert Whytt and the stretch reflex}

The separate structure and functions of sensory and motor nerves were the result of the inspired experiments of Charles Bell, and of Magendie. In the same era Marshall Hall's experiments, executed in his own home, led to his discovery of the reflex arc. It was based on what he called an "excito-motory system" 12 - of the spinal cord and nerves, shown in animals after removal of the brain. Hall introduced the term diastaltic, referring to the reflex action through the cord. The later extension of the principles of the reflex arc developed into the clinical observations of the tendon and cutaneous reflexes; but, physiologically they were vital to the understanding of the muscle stretch reflex, so brilliantly demonstrated by Liddell and Sherrington. ${ }^{34}$

It is of considerable historical interest that the salient physiological features of stretching muscle fibres had been made some 150 years earlier by Robert Whytt.

"Numberless experiments and observations show pricking a muscle causes it to contract, ... but whatever stretches the fibres of any muscle so far as to extend them beyond their usual length, excites them into contraction in about the same manner, as if they had been irritated by a sharp instrument, or acrid liquor. The motion of stretching the fibres of any muscle will be greater or less, as the muscle is more or less stretched; unless it be so extended as quite to lose its tone and become paralytic."

Whytt observed isolated muscle to twitch after death or after stimulation. Contraction varied with the strength of stimulus,

"but the effects of different stimuli depend very much upon the peculiar constitution of the nerves and fibres of the muscles to which they are applied."

He cited examples such as cold water "agreeable to the nerves of the stomach, yet which excites violent coughing ... in the windpipe." These observations presage the "doctrine of specific energies of the nerves or senses" (Muller 1801-58).

Experiments in which Whytt stimulated exposed muscle conclude with a clear prescience of the refractory period:

"An irritated muscle does not remain in a contracted state, although the stimulating cause continues to act upon it; but is alternately contracted and relaxed ... a muscle ought to remain contracted as long as the stimulus or cause of its contraction continues to act upon it; but the fact we see is otherwise; . . . it may continue for some time after it is removed, although these motions become gradually weaker, and are repeated more slowly". ${ }^{6}$
Whytt was one of the most distinguished physicians and neurophysiologists of the 18th century. He wrote of many topics, including pupillary dilatation and contraction related to light and to convergence; dilated pupils in coma due to compression of the thalami nervorum opticorum. His collected writings ${ }^{5}$ include treatises: $A n$ essay on the vital and other involuntary motions of animals (1751); Observations on sensibility and irritability of part of men and animals (1755); Observations on the nature, causes, and cure of those disorders which are commonly called nervous, hypochondriac or histeric (1764); Observations on the dropsy of the brain (1755).

Observations on sensibility and irritability... included Hales's famous decapitated frog in which 30 hours later was observed pulsation in the web of the foot, and limb movement when stimulated. After thrusting a needle down the spinal marrow, the animal was strongly convulsed and immediately after became motionless.

He also gave an exposition of the spasm and relaxation of small blood vessels in migraine ${ }^{7}$ that foreshadowed the vasospastic theories of Du Bois Reymond and Latham.

Robert Whytt (1714-66) was a Doctor of Medicine at both Rheims and St Andrews. He was Professor of the Theory of Medicine at Edinburgh when he was but 33, FRS at 38, and became President of the Royal College of Physicians of Edinburgh in 1763. He was Physician to George III in Scotland and succeeded to be 5th Baron of Bennochy.

Whytt was the great-great-great-great-grandfather of Raymond Greene, Endocrinologist and Migrainologist at the Northern Hospital, London and to his brother, the author, Graham Greene.

JMS PEARCE
304 Beverly Road,
Anlaby, Hull,
Anlaby, Hull,

1. Hall M. On the reflex function of the medulla oblongata and the medulla spinalis. Philos Trans $R$ Soc Lond $B, 1833 ; 123$. medulla

2 Hall M. Memoirs on the nervous system. Memoir II. On the true spinal marrow and the excito-motory system. London: Sherwood, Gilbert and Piper, 1837.

3 Liddell EGT, Sherrington CS. Reflexes in response to Stretch. Proceedings of the Royal Society 1924;96B:212-5.

4 Sherrington CS. Integrative action of the nervous system. New Haven: Yale, 1906. Revised with new foreword and bibliography, 1947.

5 Whytt $\mathrm{R}$. On the vital and involuntary movements of animals. Edinburgh. 1763. Cited by Jefferson G. In: Selected papers of Sir Geoffrey Jefferson. pp 73-93. London: Pitman. 1960.

6 Whytt R. The works of Robert Whytt M.D. (Published by his son). Edinburgh: Balfour, Auld and Smellie. 1768:11-12.

7 Whytt R. Observations on the nature, causes and cure of those disorders commonly called nervous, hypochondriac, or histeric. Edinburgh: Becket, Pond and Balfour, 1764 . 